\title{
Duration of lead time in screening for lung cancer
}

\author{
Jochanan Benbassat ${ }^{*}$ (0)
}

\begin{abstract}
Background: Screening for lung cancer has used chest radiography (CR), low dose computed tomography (LDCT) and sputum cytology (SC). Estimates of the lead time (LT), i.e., the time interval from detection of lung cancer by screening to the development of symptoms, have been derived from longitudinal studies of populations at risk, tumor doubling time (DT), the ratio between its prevalence at the first round of screening and its annual incidence during follow-up, and by probability modeling derived from the results of screening trials.

Objective: To review and update the estimates of LT of lung cancer.

Methods: A non-systematic search of the literature for estimates of LT and screening trials. Search of the reference sections of the retrieved papers for additional relevant studies. Calculation of LTs derived from these studies.

Results: LT since detection by CR was 0.8-1.1 years if derived from longitudinal studies; $0.6-2.1$ years if derived from prevalence / incidence ratios; 0.2 years if derived from the average tumor DT; and 0.2-1.0 if derived from probability modeling. LT since detection by LDCT was 1.1-3.5 if derived from prevalence / incidence ratios; 3.9 if derived from DT; and 0.9 if derived from probability modeling. LT since detection of squamous cell cancer by SC in persons with normal CR was 1.3-1.5 if derived from prevalence/incidence ratios; and 2.1 years if derived from the DT of squamous cell cancer.
\end{abstract}

Conclusions: Most estimates of the LT yield values of 0.2-1.5 years for detection by CR; of 0.9-3.5 years for detection by LDCT; and about 2 years or less for detection of squamous cell cancer by SC in persons with normal CR. The heterogeneity of the screening trials and methods of derivation may account for the variability of LT estimates.

Keywords: Lung cancer, Mass screening, Lead time, Cell doubling time, Chest radiography, Low dose computed radiography

\section{Background}

Screening for lung cancer assumes that the symptomatic illness is preceded by a period of pre-symptomatic disease that is detectable by chest radiography (CR), low dose computed tomography (LDCT) and sputum cytology (SC). The time interval between detection by screening and the onset of clinical manifestations is referred to as lead time (LT). Its duration has been inferred from

*Correspondence: jochanan.benbassat@gmail.com Department of Medicine (retired), Hadassah Medical Center, PO Box 3894 , 91037 Jerusalem, Israel longitudinal studies of populations at risk, randomized trials of screening for lung cancer, tumor doubling times (DT) and statistical analyzes of the results of screening trials.

Longitudinal studies have either followed prospectively populations at risk by SC [1], or reviewed retrospectively CRs that had been performed before the clinical diagnosis of lung cancer [2]. Estimates based on screening trials have inferred the duration of LT from the ratio between the prevalence of lung cancer at the first (baseline) screening round and the annual incidence of cancer during subsequent follow-up [3]. Inferences from tumor DT 
assume that a single cell of $10 \mu \mathrm{m}$ develops into a tumor by a succession of divisions at a constant DT. Therefore, one may derive the duration of LT from the tumor DT and the difference in tumor size at its detection in asymptomatic persons and in symptomatic patients [4]. Statistical analyzes have applied probability estimates on the results of screening trials. The objective of this paper is to search the literature for estimates of the LT of lung cancer and update these estimates by those derived from published screening trials by $\mathrm{SC}, \mathrm{CR}$ and LDCT.

\section{Methods}

Medline and Old Medline [5] from inception to April 2020 were searched for published estimates of LT of lung cancer, its DT and for reports of screening trials by combining the terms [carcinoma, non-small-cell lung OR carcinoma, small cell OR lung neoplasms] with (a) [mass screening] AND [randomized controlled trials] (117 hits), (b) [sputum] AND [cytology] (215 hits), and (c) [natural history] (132 hits). The reference sections of the retrieved papers were searched for additional relevant studies. Although not a systematic review of additional electronic data stores, this search probably uncovered the main relevant studies, and possible omissions would not have changed the study main conclusions.

\section{Results}

\section{Longitudinal studies}

Prospective serial SC examinations of uranium miners between 1957 and 1970 found sequential abnormalities that consisted of mild atypia followed by moderate atypia, marked atypia and carcinoma in situ [1]. On the average, 2.5 years after detection of carcinoma in situ cells in the sputum, the patients developed invasive carcinoma. 'Invasive carcinoma' was reported to have been diagnosed "cytologically, clinically or at autopsy" [1]; however, the proportion of invasive cancers, which were also radiographically or clinically evident, was not reported.

A 1964 retrospective study of patients with lung cancer, in whom CRs had been made before the definitive diagnosis, revealed an interval between the first CR signs and the first symptoms of $0.8-1$ year [2]. Another retrospective study inferred the duration of the LT from the intervals between CR examinations of patients who adhered to the screening protocol (6 months), and the patients who did not (19.5 months). The 13.5 months ( $=1.1$ years) difference was viewed as an approximation of the interval between CR and clinical detection of lung cancer [6].

\section{Prevalence/annual incidence ratios}

Estimates of LTs derived from prevalence/annual incidence ratios in seven randomized trials of screening by CR ranged between 0.6 and 2.1 years (Table 1). Those derived from controlled randomized trials of screening by LDCT were between 1.1 and 3.5 years (Table 2). Table 3 summarizes LTs derived from randomized trials of screening after selection of cancers detected by SC alone in patients with normal CR. Although comprising only $25 \%$ to $40 \%$ of all lung cancers, squamous cell lung cancer is practically the only cell type detected by SC in individuals with normal CR. Squamous cell cancer commonly originates centrally and grows as a thin sheet replacing the mucosa, thus escaping radiographic detection while desquamating malignant cells into the sputum [26]. The prevalence / annual incidence ratios of squamous cell lung cancer detected by SC screening only, suggested a LT between cytological and clinical detection of squamous cell lung cancer of 1.2 to 1.8 years.

\section{Tumor doubling time}

The commonly used model of tumor growth kinetics assumes an exponential expansion from a single cell at a constant DT that may be estimated by the increase in tumor size on serial CRs [4]. With each doubling of volume, the tumor increases its diameter by approximately 1.26 (the cube root of 2). The average diameter of lung cancer at clinical diagnosis is $33 \mathrm{~mm}$ (after 35 doublings) [4]; that at detection by LDCT in asymptomatic persons is $16 \mathrm{~mm}$ (after 32 doublings); and that at detection by $C R$ is $30 \mathrm{~mm}$ (after 34.5 doublings) [27]. The size of radiologically occult lung cancer detected by SC, was estimated by applying the equation of Schwartz [28]:

Tumor volume $=\pi / 6 * \mathrm{ab}^{2}$

( $\mathrm{a}=$ Axial length in $\mathrm{mm}$ and $\mathrm{b}=$ Approximate average maximal depth in $\mathrm{mm}$ ).

on the data reported by Woolner et al. [29] in 68 patients with occult lung cancer, and calculated the average volume of their tumors as $135 \mathrm{cmm}$. For a round tumor of the same volume, this implies a diameter of about $6 \mathrm{~mm}$ (after 27.5 doublings). According to this model, one may derive the duration of LT by multiplying the DT of the tumor by the number of doublings needed to reach the average diameter at clinical detection: 7.5 after detection by SC in persons with normal CR; 3 after detection by LDCT; and 0.5 after detection by CR.

The DTs of lung cancer were retrieved from the 2008 review of the literature by Detterbeck and Gibson [27]. They found that clinically detected lung cancers had an average DT of 136 days; lung cancers detected by screening by CR had average DT of 150 days; and lung cancers detected by screening by LDCT had average DT of 480 days. The longer DTs of screen detected cancers is consistent with length bias: screening is more likely to detect selectively slow growing cancers. For squamous 


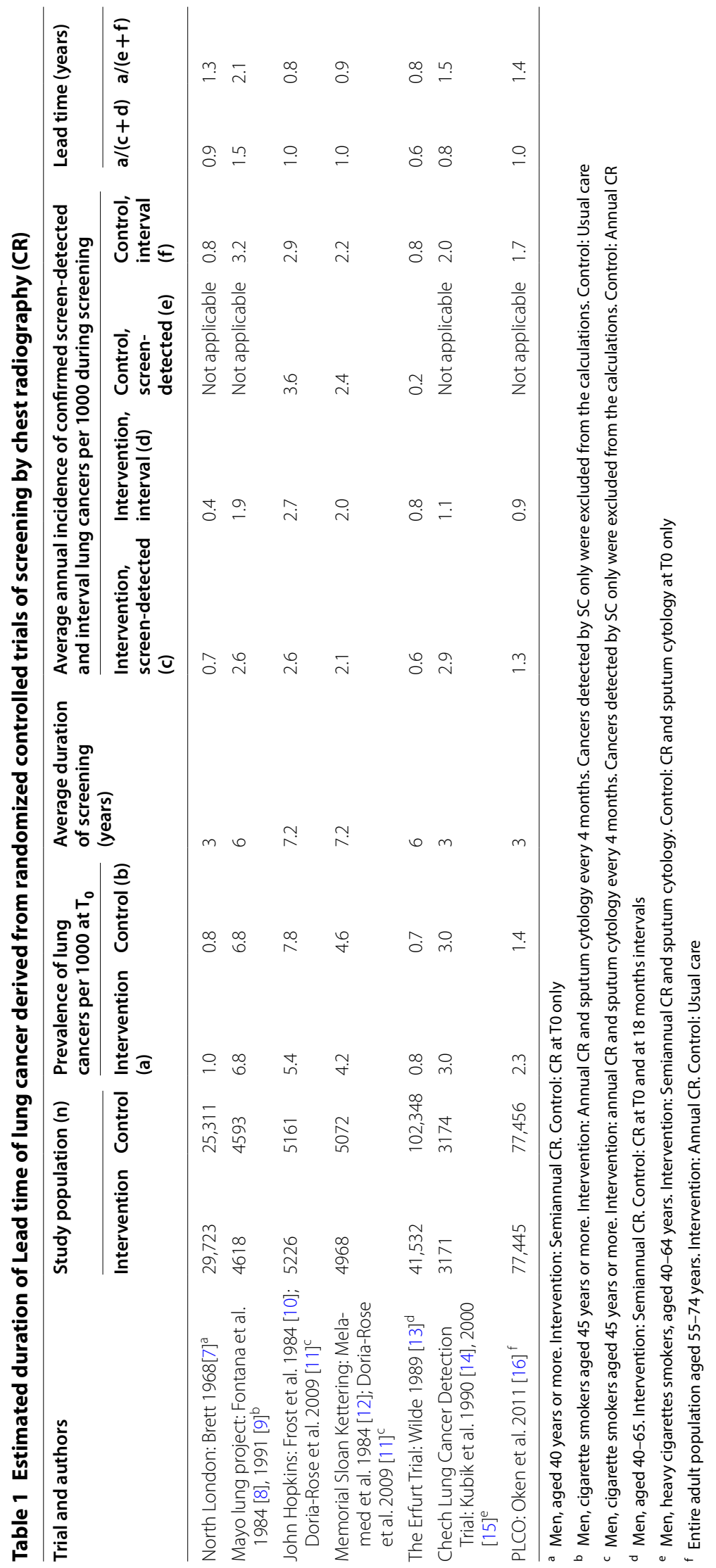




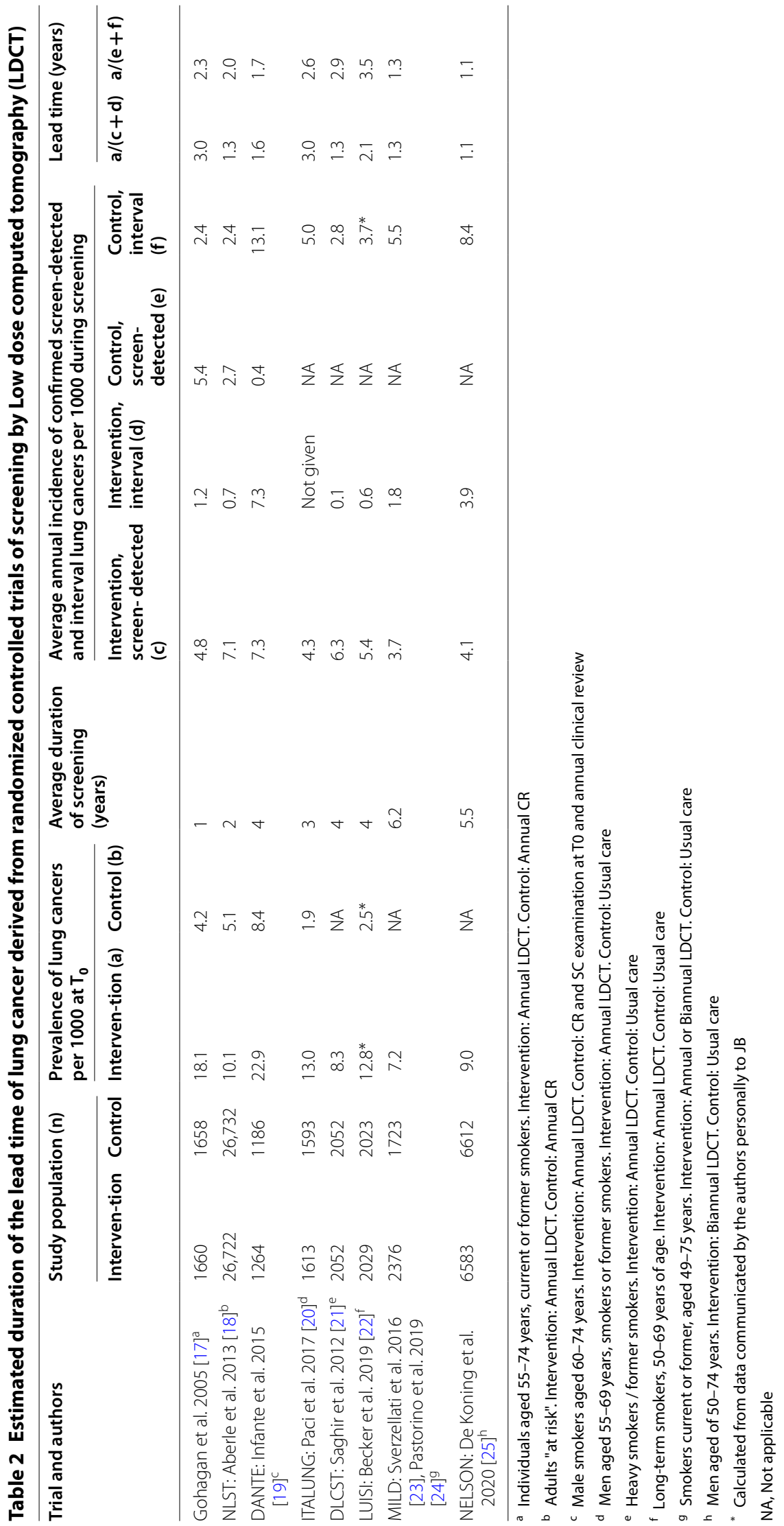




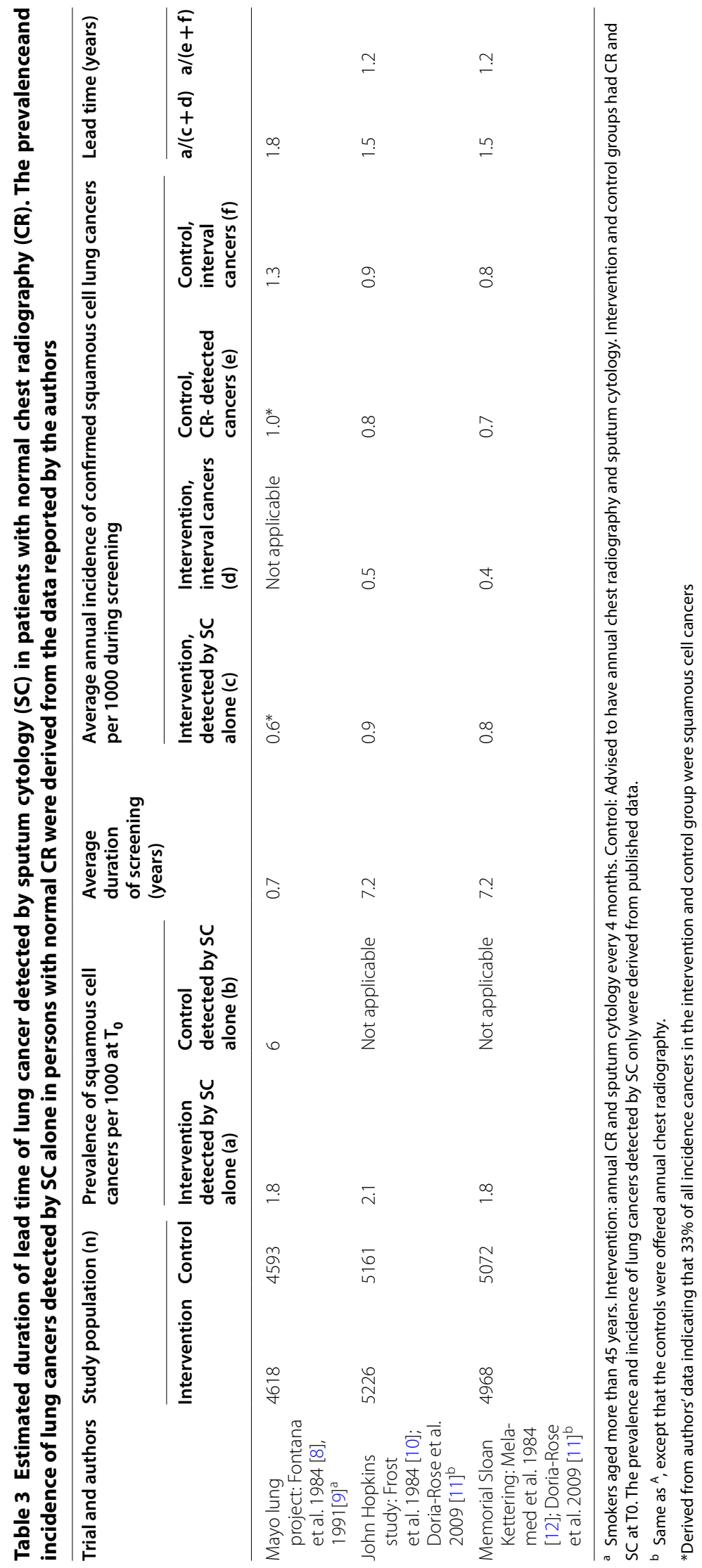


cell cancer, the average DT was 104 days for clinical detection; 105 days for detection by screening by CR, and 122 days for detection by screening by LDCT. The respective DTs for adenocarcinoma were 169, 223 and 576 days; and for broncho-alveolar cancer-250, 250 and 764 days.

Therefore, LT of lung cancer would be about 3.9 years after detection by LDCT (three doublings, DT 480 days), 0.2 years after detection by CR (half a doubling, DT 150 days) and 2.1 years after detection by SC in persons with normal CR (7.5 doublings, DT 104 days).

\section{Probability modeling derived from the results of screening trials}

A number of statistical methods have been proposed to derive LT from randomized screening trials for cancer by focusing on screen detected cases and by ignoring interval cases (with $\mathrm{LT}=0$ ) [30]. In 2018, Liu et al. [30] used Bayesian posterior samples of key parameters of the NLST-LDCT data to carry out simulations of LT by age and duration of screening intervals. They found that the probability of no-early detection (interval cases) increased with longer screening intervals. Thus, a male heavy smoker had $12 \%$ chance of no-early detection with annual screening, and $36 \%$ chance with bi-annual screening. The mean LT decreased from 0.9 (standard error-0.7) years with annual screening, to 0.6 (standard error-0.7) years with bi-annual screening.

\section{Discussion}

Derived LTs have fluctuated between 0.2 and 2.1 years since detection by CR 0.9 to 3.9 years since detection by LDCT; and 1.3 and 2.1 years since detection by SC in persons with normal chest $\mathrm{x}$-ray (squamous cell cancer).
The modes of LT and its range of probability density curves derived by probability modeling that includes interval cases were $0.24(0-2.0)$ years since detection by CR [31], and $0.9(0-3.0)$ years since detection by LDCT [30]. Table 4 summarizes the main findings of this survey.

The main limitations of this study are the methodological differences and possible erroneous assumptions of the approaches to the estimation of LT. First, estimates of LT derived from screening trials may have been biased by the heterogeneity in their study populations (see footnotes of Tables 1 and 2). Some trials included men only, while others included men and women; some trials included smokers only, while others included current, former or never smokers. Some trials conducted a single round of follow up examinations, in addition to the baseline round, while other performed several annual examinations. There was also a marked heterogeneity of the histology of the detected lung cancers (data not shown), and histologically different cancers have different LTs.

Second, selection bias may have affected the findings by Saccomanno et al. [1]. As noted by the authors, the restriction of their report to patients who developed invasive carcinoma during the period of observation, may have selected those with a shorter interval between carcinoma in situ to invasive carcinoma. Therefore, the observed 2.5-year interval may have underestimated the time interval between carcinoma in situ and invasive squamous cell cancer.

Third, the estimates of LTs may have been biased by erroneous assumptions when lung cancer becomes radiologically detectable. These assumptions are probably valid for extra-bronchial coin lesions, but not for endobronchial squamous cell cancers that become radiographically evident at a much larger size. Therefore,

Table 4 Estimates of lead time of lung cancer (years) by methods of study

\begin{tabular}{|c|c|c|c|}
\hline Estimates derived from & $\begin{array}{l}\text { From cytological } \\
\text { to clinical }\end{array}$ & $\begin{array}{l}\text { From low dose computed } \\
\text { tomography to clinical }\end{array}$ & From radiographic to clinical \\
\hline Follow up (longitudinal studies) & $2.5^{\mathrm{a}}$ & & $0.8-1.1$ \\
\hline Prevalence / incidence ratios all histologic types & & $1.1-3.5$ & $0.6-2.1$ \\
\hline Prevalence / incidence ratios squamous cell cancer only & $1.3-1.5$ & & $1.2-1.8^{b}$ \\
\hline Doubling time, all histologic types & & $3.9^{c}$ & $0.2^{d}$ \\
\hline Doubling time, squamous cell lung cancer only & $2.1^{\mathrm{e}}$ & $1.0^{f}$ & $0.14^{\mathrm{g}}$ \\
\hline $\begin{array}{l}\text { Statistical methods applied on controlled trials (modes and range } \\
\text { of probability density curves, and means and standard errors) }\end{array}$ & & $\begin{array}{l}\text { Mode: } 0.9(0-3.0) \\
\text { Mean: } 0.87(0.69)\end{array}$ & $\begin{array}{l}\text { Mode: } 0.24(0-2.0) \\
\text { Mean: } 1.0(1.7)\end{array}$ \\
\hline
\end{tabular}

a Time interval between carcinoma in situ and invasive carcinoma

b Calculated from the data reported by Doria-Rose et al. 2009 [11] on the prevalence and incidence of squamous cell cancers detected by CR

c Assuming a doubling time of 480 days [27]

d Assuming a doubling time of 150 days [27]

e Assuming a doubling time of 104 days [27]

f Assuming a doubling time of 122 days [27]

9 Assuming a doubling time of 105 days [27] 
although LDCT is considered to be the most accurate mass screening modality, it is uncertain whether addition of SC can improve the sensitivity of screening by detecting squamous cell lung cancer before LDCT. It is also questionable whether the equation by Schwartz for extra-bronchial lesions [28] may be applied for occult lung cancer.

A fourth limitation of this study is the uncertainty regarding tumor growth kinetics. On the one hand, a 2018 study that evaluated growth patterns of untreated lung cancer confirmed that the exponential model explains the development of both sub-solid and solid lung cancers [32]. On the other hand, the proliferation curves of almost all animal tumors may be better described by a Gomperzian function [33] that predicts progressively longer DTs as the tumor gets larger, and thereby, a shorter period of preclinical growth than the exponential model, and longer survival after diagnosis.

Both models assume that, if untreated, all cases detected by screening would eventually surface clinically. This assumption is supported by the finding that two thirds of the lung cancer patients detected by SC only [34], and all clinical Stage I lung cancers detected by CR [35] died from lung cancer within 10 years. On the other hand, the estimated average DT of 480 days of cancers detected by screening by LCDT [27] predicts a median survival for lung cancer patients of more than 10 years, rather than the less than a year observed in patents with clinical lung cancer. Therefore, it is possible that LDCT detects mainly slow-growing cancers or tumors, which may not progress to advanced disease [36].

Future research may first, consist of systematic reviews of the literature for screening trials for lung cancer. However, it seems that their heterogeneity with regard to study populations, control populations, and time intervals between screening preclude meta-analysis. Second, $\mathrm{SC}$ cytology may be considered again as a screening test, in addition to LDCT. Finally, an effort should be made to resolve the inconsistency between the observed survival of patients with lung cancer detected by LDCT and their calculated LT on the basis of their doubling time.

\section{Abbreviations \\ CR: Chest radiography; LDCT: Low dose computed tomography; SC: Sputum cytology; LT: Lead time; DT:Tumor doubling time.}

\section{Acknowledgements \\ None}

\section{Authors' contributions}

I am the only author, and have read and approved the final manuscript.

Funding

None.
Availability of data and materials

Not applicable.

Ethics approval and consent to participate

Not applicable.

Consent for publication

Not applicable.

Competing interests

The authors declare no competing interests.

Received: 7 June 2020 Accepted: 20 December 2020

Published online: 06 January 2021

\section{References}

1. Saccomanno G, Archer VE, Auerbach O, Saunders RP, Brennan IM. Development of carcinoma in the lung as reflected in exfoliated cells. Cancer. 1974;33:256-69.

2. Riegler LG. The natural history of untreated lung cancer. Ann N Y Acad Sci. 1964;114:755-66.

3. Henschke Cl, Salvatore M, Cham M, Powell CA, DiFabrizio L, Flores R, Kaufman A, Eber C, Yip R, Yankelevitz DF. Baseline and annual repeat rounds of screening implications for optimal regimens of screening. Eur Radiol. 2018;28:1085-94

4. Geddes DM. The natural history of lung cancer. A review based on rates of tumor growth. Brit J Dis Chest. 1979;73:1-17.

5. Horowitz GL, Bleich HL. PaperChase: a computer program to search the medical literature. New Engl J Med. 1981;305:924-30.

6. Weiss $W$. Implications of tumor growth rate for the natural history of lung cancer. J Occup Med. 1984;26:345-52.

7. Brett GZ. The value of lung cancer detection by six-monthly chest radiographs. Thorax. 1968:23:414

8. Fontana RS, Sanderson DR, Taylor WF, et al. Early lung cancer detection: results of the initial (prevalence) radiologic and cytologic screening in the Mayo clinic study. Am Rev Respir Dis. 1984;130:561-5.

9. Fontana RS, Sanderson DR, Woolner WB, Taylor WF, Miller WE, Muhm JR, Bernatz PE, Payne WS, Pairolero PC, Bergstralh EJ. Screening for lung cancer a critique of the mayo lung project. CANCER Supplement. 1991;67:1155-67.

10. Frost JK, Ball WC, Levin ML. Early lung cancer detection: results of the initial (prevalence) radiologic and cytologic screening in the John Hopkins study. Am Rev Resp Dis. 1984;130:549-54.

11. Doria-Rose VP, Marcus PM, Szabo E. Randomized controlled trials of the efficacy of lung cancer screening by sputum cytology revisited: a combined mortality analysis from the Johns Hopkins lung project and the Memorial Sloan-Kettering lung study. Cancer. 2009;115:5007-17.

12. Melamed MR, Flehinger BJ, Zaman MB, Heelan RT, Perchick WA, Martini N. Screening for early lung cancer. results of the memorial sloan-kettering study In New York. Chest. 1984;86:44-53.

13. Wilde J. A 10-year follow-up of semi-annual screening for early detection of lung cancer in the Erfurt County. GDR Eur Respir J. 1989;2:656-862.

14. Kubik AK, Khlat M, Erban J, Polak J, Adamec M. Lack of benefit from semi-annual screening for cancer of the lung: follow-up report of a randomized controlled trial on population of high-risk males in Czechoslovakia. Int J Cancer. 1990;45:26-33.

15. Kubık AK, Maxwell Parkin D, Zatloukal P. Czech study on lung cancer screening post-trial follow-up of lung cancer deaths up to year 15 since enrollment. Cancer. 2000;89:2363-8.

16. Oken MM, Hocking WG, Kvale PA, Andriole GL, Buys SS, Church TR, Crawford ED, Fouad N, Isaacs C, Reding DJ, Weissfeld JL, Yokochi LA, O'Brien B, Ragard LR, Rathmell JM, Riley TL, Wright P, Caparaso N, Hu P, Izmirlian G, Pinsky PF, Prorok PC, Kramer BS, Miller AB, Gohagan JK, Berg CD. Screening by chest radiograph and lung cancer mortality: the Prostate, Lung, Colorectal, and Ovarian (PLCO) randomized trial. JAMA. 2011;306:1865-73.

17. Gohagan JK, Marcus PM, Fagerstrom RM, Pinsky PF, Kramer BS, Prorok PC, et al. Final results of the Lung Screening Study, a randomized feasibility 
study of spiral CT versus chest $X$-ray screening for lung cancer. Lung Cancer. 2005;47:9-15.

18. Aberle DR, DeMello S, Berg CD, Black WC, Brewer B, Church TR, Clingan KL, Duan F, Fagerstrom RM, Gareen IF, Gatsonis CA, Gierada DS, Jain A Jones GC, Mahon I, Marcus PM, Rathmell JM, Sicks J. Results of the two incidence screenings in the National Lung Screening Trial. N Engl J Med. 2013;369:920-31

19. Infante M, Cavuto S, Lutman FR, Passera E, Chiarenza M, Chiesa G, Brambilla G, Angeli E, Aranzulla G, Chiti A, Scorsetti M, Navarria P, Cavina R, Ciccarelli M, Roncalli M, Destro A, Bottoni E, Voulaz E, Errico V, Ferraroli G, Finocchiaro G, Toschi L, Santoro A, Alloisio M. Long-term follow-up results of the DANTE Trial, a randomized study of lung cancer screening with spiral computed tomography. Am J Respir Crit Care Med. 2015;191:1 166-75.

20. Paci E, Puliti D, Lopes Pegna A, Carrozzi L, Picozzi G, Falaschi F, Pistelli F, Aquilini F, Ocello C, Zappa M, Carozzi FM, Mascalchi M. Mortality, survival and incidence rates in the ITALUNG randomized lung cancer screening trial. Thorax. 2017;72:825-31.

21. Saghir Z, Dirksen A, Ashraf H, Skjøldstrup Bach K, Brodersen J, Clementsen PF, Døssing M, Hansen H, Kofoed KF, Larsen KR, Mortensen J, Rasmussen JF, Seersholm N, Guldhammer Skov B, Thorsen H, Tønnesen P, Pedersen JH. CT screening for lung cancer brings forward early disease. The randomised Danish Lung Cancer Screening Trial: status after five annual screening rounds with low-dose CT. Thorax 2012; 67: $296 \mathrm{e}$.

22. Becker N, Motsch E, Trotter A, Heussel CP, Dienemann H, Schnabel PA, Kauczor HU, Maldonado SG, Miller AB, Kaaks R, Delorme S. Lung cancer mortality reduction by LDCT screening - Results from the randomized German LUSI trial. Int J Cancer. 2020;146:1503-13.

23. Sverzellati N, Silva M, Calareso G, Galeone C, Marchianò A, Sestini S, Sozzi G, Pastorino U. Low-dose computed tomography for lung cancer screening: comparison of performance between annual and biennial screen. Eur Radiol. 2016:26:3821-9.

24. Pastorino U, Silva M, Sestini S, Sabia F, Boeri M, Cantarutti A, Sverzellati N, Sozzi G, Corrao G, Marchiano A. Prolonged lung cancer screening reduced 10-year mortality in the MILD trial: new confirmation of lung cancer screening efficacy. Ann Oncol. 2019;30:1162-9.

25. de Koning HJ, Van der Aalst CM, de Jong PA, Scholten ET, Nackaerts $\mathrm{K}$, Heuvelmans MA, Lammers JWJ, Weenink C, Yousaf-Khan U, Horeweg $\mathrm{N}$, van Westeinde S, Prokop M, Mali WP, Mohamed Hoesein FAA, van Ooijen PMA, Aerts JGJV, den Bakker MA, Thunnissen E, Verschakelen J, Vliegenthart R, Walter JE, ten Haaf K, Groen HJM, Oudkerk M. Reduced lung-cancer mortality with volume CT screening in a randomized trial. N Engl J Med. 2020;382:503-13.
26. Tao LC. Cytologic diagnosis of radiographically occult squamous cell cancer of the lung. Cancer. 1982;50:1580-6.

27. Detterbeck FC, Gibson CJ. Turning gray: the natural history of lung cancer over time. J Thorac Oncol. 2008;3:781-92.

28. Schwartz M. A biomathematical approach to clinical tumor growth. Cancer. 1961;14:1272-94.

29. Woolner LB, Fontana RS, Cortese DA, et al. Roentgenographically occult lung cancer: pathologic findings and frequency of multicentricity during a 10-year period. Mayo Clin Proc. 1984:59:453-66.

30. Liu R, Perez A, Wu D. The lead time distribution in the National Lung Screening

31. Trial study. Journal of Healthcare Informatics Research 2018; 2: 353-366.

32. Wu D, Kafadar K, Rosner GL, Broemeling LD. The Lead Time Distribution When Lifetime is Subject to Competing Risks in Cancer Screening. The International Journal of Biostatistics. 2012; 8: Iss. 1, Article 6.

33. Mets OM, Chung K, Zanen P, Scholten ET, Veldhuis WB, van Ginneken B, Prokop M, Schaefer-Prokop CM, de Jong PA. In vivo growth of 60 nonscreening detected lung cancers: a computed tomography study. Eur Respir J. 2018;4:51.

34. Vaghi C, Rodallec A, Fanciullino R, Ciccolini J, Mochel JP, Mastri M, Poignard C, Ebos JML. Benzekry S Population modeling of tumor growth curves and the reduced Gompertz model improve prediction of the age of experimental tumors. PLoS Comput Biol. 2020. https://doi.org/10.1371/ journal.pcbi.1007178.

35. Sato M, Saito Y, Endo C, Sakurada A, Feller-Kopman D, Ernst A, Kondo T. The natural history of radiographically occult bronchogenic squamous cell carcinoma: a retrospective study of overdiagnosis bias. Chest. 2004;126:108-13.

36. Sobue T, Suzuki T, Matsuda M, Kuroishi T, Ikeda S, Naruke T, and The Japanese Lung Cancer Screening Research Group. Survival for Clinical Stage I Lung Cancer Not Surgically Treated Comparison between ScreenDetected and Symptom-Detected Cases. Cancer 1992, 69: 685-692.

37. Bach PB. Is our natural-history model of lung cancer wrong? Lancet Oncol. 2008;9:693-7.

\section{Publisher's Note}

Springer Nature remains neutral with regard to jurisdictional claims in published maps and institutional affiliations.
Ready to submit your research? Choose BMC and benefit from:

- fast, convenient online submission

- thorough peer review by experienced researchers in your field

- rapid publication on acceptance

- support for research data, including large and complex data types

- gold Open Access which fosters wider collaboration and increased citations

- maximum visibility for your research: over 100M website views per year

At BMC, research is always in progress.

Learn more biomedcentral.com/submissions 